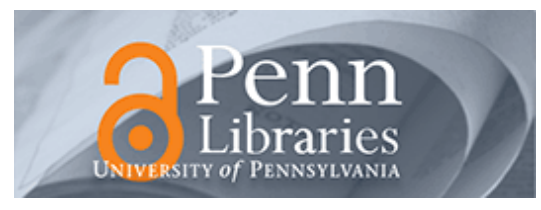

University of Pennsylvania

ScholarlyCommons

Marketing Papers

Wharton Faculty Research

4-2007

\title{
Alone in a Crowd of Sheep: Asymmetric Perceptions of Conformity and Their Roots in an Introspection Illusion
}

Emily Pronin

Jonah A. Berger

University of Pennsylvania

Sarah Molouki

Follow this and additional works at: https://repository.upenn.edu/marketing_papers

Part of the Cognition and Perception Commons, Cognitive Psychology Commons, Community Psychology Commons, Interpersonal and Small Group Communication Commons, Marketing Commons, Social Influence and Political Communication Commons, and the Social Psychology Commons

\section{Recommended Citation}

Pronin, E., Berger, J. A., \& Molouki, S. (2007). Alone in a Crowd of Sheep: Asymmetric Perceptions of Conformity and Their Roots in an Introspection Illusion. Journal of Personality and Social Psychology, 92 (4), 585-595. http://dx.doi.org/10.1037/0022-3514.92.4.585

This paper is posted at ScholarlyCommons. https://repository.upenn.edu/marketing_papers/292

For more information, please contact repository@pobox.upenn.edu. 


\title{
Alone in a Crowd of Sheep: Asymmetric Perceptions of Conformity and Their Roots in an Introspection Illusion
}

\begin{abstract}
The results of 5 studies showed that people see others as more conforming than themselves. This asymmetry was found to occur in domains ranging from consumer purchases to political views. Participants claimed to be less susceptible than their average peers to broad descriptions of social influences, and they also claimed to be less susceptible than specific peers to specific instances of conformity. These studies further demonstrated that this asymmetry is not simply the result of social desirability, but it is also rooted in people's attention to introspective versus behavioral information when making conformity assessments. The participants displayed an introspection illusion, placing more weight on introspective evidence of conformity (relative to behavioral evidence) when judging their own susceptibility to social influence as opposed to someone else's. Implications for self-other asymmetries, implicit social influence, and interpersonal conflict are discussed.
\end{abstract}

\section{Keywords}

conformity, social influence, self-perception, introspection illusion, actor-observer

\section{Disciplines}

Business | Cognition and Perception | Cognitive Psychology | Community Psychology | Interpersonal and Small Group Communication | Marketing | Social Influence and Political Communication | Social

Psychology 
Alone in a Crowd of Sheep:

Asymmetric Perceptions of Conformity and their Roots in an Introspection Illusion

\author{
Emily Pronin \\ Jonah Berger \\ Princeton University \\ Stanford University
}

\author{
Sarah Molouki \\ Princeton University
}

Forthcoming, Journal of Personality and Social Psychology 


\begin{abstract}
Five studies show that people see others as more conforming than themselves. This asymmetry is documented in domains ranging from consumer purchases to political views. Participants claimed to be less susceptible than their average peers to broad descriptions of social influences, and they also claimed to be less susceptible than specific peers to specific instances of conformity. These studies further demonstrated that this asymmetry is not simply the result of social desirability, but it is also rooted in people's attention to introspective vs. behavioral information when making conformity assessments. Our participants displayed an introspection illusion, placing more weight on introspective evidence of conformity (relative to behavioral evidence) when judging their own susceptibility to social influence as opposed to someone else’s. Implications for self-other asymmetries, implicit social influence, and interpersonal conflict are discussed.
\end{abstract}




\section{Alone in a Crowd of Sheep: Asymmetric Perceptions of Conformity And their Roots in an Introspection Illusion}

It is easy in the world to live after the world's opinion; it is easy in solitude to live after our own; but the great man is he who in the midst of the crowd keeps with perfect sweetness the independence of solitude.

—Ralph Waldo Emerson (1841)

The power of social influence is undeniable. People wear the same styles of clothing as their friends, drive the same cars as their neighbors, vote the same politics as their parents, and read the same books as their favorite celebrities. Social commentators ranging from playwrights to sociologists have long lamented people's tendency to conform in their tastes, preferences, aspirations, and behaviors (e.g., Emerson, 1841; Ionesco, 1958; Thoreau, 1850; Whyte, 1956). The study of social influence, and of conformity in particular, is also at the heart of social psychology, which Gordon Allport (1985, p. 3) defined as "an attempt to understand and explain how the thoughts, feelings and behaviors of individuals are influenced by the actual, imagined, or implied presence of others." In fact, many of the classic studies in our field (e.g., Asch, 1956; Latane \& Darley, 1968; Milgram, 1974; Newcomb, 1943; Schachter \& Singer, 1962; Sherif, 1937) have been about some form of conformity or social influence.

Studies of social influence have demonstrated people's tendency to conform in a wide range of circumstances. People conform in their judgments of both ambiguous stimuli (Sherif, 1936) and unambiguous stimuli (Asch, 1956). They conform on trivial matters, such as their preferences for different types of instant coffee (Burnkrant \& Cousineau, 1975), and on more weighty matters, such as their tendency to recycle (Cialdini, 2003). And, people conform to social influence from a wide variety of sources, including people they look up to (Newcomb, 1943), peers they do not personally know (Latane \& Darley, 1968), relatively abstract reference groups (Cohen, 2003), and social norms they privately reject (Prentice \& Miller, 1996).

\section{Asymmetric Perceptions of Conformity}

Everyday experience and decades of research make clear that instances of conformity are all around us. The contention of the present article, though, is that there is one place where these instances are difficult to see: that is, in ourselves. We predict that when it comes to detecting the impact of social influence, people will see themselves as “alone in a crowd of sheep.”

Although conformity and social influence have been the subject of many studies, few studies have examined perceptions of social influence or conformity. However, observations from some existing studies are worthy of note. In their studies demonstrating the effect of others' inaction on bystander intervention, Latane and Darley (1968) reported that most participants denied (in debriefings) that their behavior had been socially influenced. Similarly, the majority of participants who conformed to group norms in Sherif's (1937) classic autokinetic experiment denied such influence and instead claimed to have formed an opinion before hearing from others in the group. More recently, Cohen (2003) found that participants' support of various domestic policies was powerfully shaped by the purported position of their political party, but they denied that influence (even while recognizing that it would affect the average Democrat or Republican). 
Everyday experience also suggests that we may fail to recognize our own susceptibility to social influence. When buying the same pop music album as our friends, or purchasing the same car as our coworker, we rarely think we have succumbed to social influence: We say we bought the album for the band's sound, and the car for its superb handling and repair record. Similarly, when hearing about classic experiments on conformity, our students often marvel at how far people will go to conform, but note that they would never act that way in the same situation.

\section{Sources of the Asymmetry}

The opening of this article suggests that conformity is often viewed as undesirable. Indeed, self-serving motives are likely to contribute to people's persistent denials of conformity. We argue, however, that a cognitive process underlying evaluations of conformity also biases those judgments (in a way that is likely to serve self-enhancement needs). Specifically, assessments of conformity can rely on information of two different sorts. They can rely on observable behavior (e.g., Harold's recent car purchase was clearly conformist since he bought the same car that a number of his coworkers own; Marjorie conforms in her eating habits - she always orders the same entrée as her date), or they can rely on introspections (I didn't conform in buying that car because its popularity never crossed my mind; I don't conform in my eating habits - I always order what I think I would enjoy the most). The proposed cognitive process at the heart of conformity-related assessments involves a different weighting of these two sorts of information when considering self vs. others - i.e., with self-assessments being more likely than other-assessments to weight introspective information above behavioral information.

A greater reliance on introspective evidence at the expense of considering behavioral evidence may lead to underestimations of the impact of social influence since such influence often occurs without conscious awareness or intent. People nonconsciously mimic the motor behavior and movements of social interaction partners (Chartrand \& Bargh, 1999; also Word, Zanna, \& Cooper, 1974), and they nonconsciously adopt their partners' self-presentation styles (Vorauer \& Miller, 1997). In addition, people’s goal-oriented behaviors are influenced by nonconscious social cues (Fitzsimons \& Bargh, 2003), and people are more likely to conform to others' behavior after being nonconsciously primed with conformity-related words (Epley \& Gilovich, 1999). Furthermore, research on "mere exposure" (Zajonc, 1968) suggests that people will come to like the clothing that those around them wear, and the cars that those around them drive, without realizing that such influence has occurred - and possibly without even realizing that they have been exposed to the relevant influence (Kunst-Wilson \& Zajonc, 1980).

\section{The Introspection Illusion}

To the extent that conformity occurs nonconsciously, evidence for it will necessarily escape introspection. We suggest that one source of the predicted asymmetry in conformity assessments involves an introspection illusion (Pronin, Gilovich, \& Ross, 2004; Pronin \& Kugler, 2006), whereby people focus on internal information at the expense of behavioral information in making self-assessments, but not other-assessments. Previous research suggests that people show such a tendency. People tend to use information about perceived thoughts, motives, and intentions as a basis for making inferences about their own, but not others', future behaviors, altruistic tendencies, and commissions of bias (Epley \& Dunning, 2000; Kruger \& Gilovich, 2004; Pronin \& Kugler, 2006). By contrast, people look to behavior as a basis for 
inferring other people's, but not their own, intentions and traits (Jones \& Davis, 1965; Jones \& Nisbett, 1972). Studies directly exploring attention to internal states vs. behavior suggest that people view behavior as more revealing of others, and internal states as more revealing of the self (Andersen \& Ross, 1984; Pronin, Kruger, Savitsky, \& Ross, 2001; Pronin \& Kugler, 2006).

In their classic article on the actor-observer bias, Jones and Nisbett (1972) argued that differences in access to introspective information are a critical source of actor-observer differences in attribution. This argument suggests that if we knew another person's conformityrelated introspections, for example our neighbor's thoughts before deciding to buy that top-ofthe-line outdoor barbecue, our judgments of conformity would resemble that person's. However, the predicted illusion of introspection involves an over-weighting of internal states (relative to behavior) that is not entirely due to increased access to that information, but also to increased valuation of it. When assessing the impact of social influence on ourselves, we are likely to view introspections as a highly useful source of information, and behavioral evidence (e.g., whether others on the block purchased the pricey barbecue before we did) as a less useful source. By contrast, when assessing the impact of social influence on others, we are less likely to privilege thoughts over behavior. Whereas we may feel that knowing our introspections is enough for us to determine whether we have conformed, when it comes to judging our neighbor's conformity, we may feel that knowing his behavior is at least as valuable as knowing his interest in Consumer Reports' barbecue ratings, or his exhilaration at grilling the perfect rib-eye steak in his backyard (or his absence of any conscious desire to impress the wealthier families on the block).

\section{Overview of the Present Research}

We predict that people will more readily detect the impact of social influence on others than on themselves. Furthermore, we expect that when making judgments about the impact of social influence on themselves, actors will be inclined, more than observers, to focus on introspective information and neglect behavioral information. The present studies investigate these hypotheses by first seeking to document the predicted self_-other asymmetry in perceptions of social influence and also seeking to rule out the possibility that the asymmetry purely reflects social desirability motives (Studies 1-2). The research then seeks to test whether the asymmetry is rooted in part in self-other differences in people's consideration and valuation of introspective versus behavioral information about conformity (Studies 3-5).

\section{Study 1: Perceptions of Social Influence in Varied Domains}

In our initial study, we sought to test the general hypothesis of a self-other asymmetry in perceptions of conformity and social influence. Across a variety of different reference groups and social contexts, we predicted that people would see themselves as less conforming than their peers. This study also began our exploration of underlying mechanism. It examined possible effects of the introspection illusion, and of social desirability or self-enhancement concerns, on denials of personal conformity. We expected that participants would be more inclined to deny their own conformity (relative to their peers') not only in cases where such influences were less desirable, but also in cases where those influences were more likely to elude conscious introspection. 


\section{Method}

Participants

A total of 44 undergraduate students at Princeton University (23 men and 21 women) participated in exchange for course credit.

\section{Procedure and Questionnaire}

Participants' questionnaire asked them to assess their own susceptibility, compared to the average Princeton student, to 16 examples of conformity (i.e., influence of: conversation partners' gestures on one's own gestures, dining partners on dining etiquette, local residents' behavior on behavior in foreign countries, other students' behavior on asking questions in class, Hollywood celebrities on social and moral values, others' behavior in a cafeteria on cleaning up after oneself, bystanders' actions on intervention in emergencies, other drivers on driving speed/courtesy, others' attire on dress in formal or religious settings, others' calm behavior in long lines on one's own calmness, media on political views, other pedestrians on one's own walking patterns, peers on engaging in risky behaviors, attractiveness norms on first impressions, reference groups on treatment of eccentric individuals, and peers on social consumption of alcohol).

Participants first read a description of each influence, such as the following:

Everyday observation, and some psychological research, suggests that people unconsciously adjust the gestures that they use in social situations in order to make the people that they interact with feel more comfortable. For example, if a person is talking to someone who has their legs crossed or their hands placed on the table, the person might end up crossing their own legs or placing their own hands on the table. ${ }^{1}$

After reading about each example, participants were asked how much they were affected by that "tendency," compared to the average Princeton student $(1=$ Much less than average student, $4=$ Same amount, 7 = Much more than average student).

\section{Item Ratings}

Each example of conformity was rated (by two undergraduate and two graduate psychology students, all uninformed of our hypotheses) in terms of its desirability and tendency to operate consciously. On 5-point scales, raters assessed "how desirable it is for a person to be influenced by that influence," and "how likely it is that a person who showed that influence would be aware that they were being influenced by it and would intentionally be influenced in that way.” Reliability was good for both ratings (Cronbach’s $\alpha$ ’s = .91 and .84, respectively).

\section{Results and Discussion}

Participants showed a general tendency to view themselves as less susceptible than their peers to various forms of social influence. Across the 16 different influences, they rated themselves as less susceptible than their average fellow student ( $M=3.69$, where 4 signifies "same" susceptibility as the average student, and lower numbers signify less susceptibility). 
Compared with the scale midpoint of 4 , their lower ratings represented a significant tendency to deny personal susceptibility to conformity, $t(42)=4.62, p<.0001$.

\section{The Role of the Introspection Illusion and of Social Desirability}

We next examined whether participants' tendency to impute social influence more to others than the self was affected by social desirability and introspective availability. We conducted regression analyses within participants (using coders' ratings of desirability and introspective availability as predictors of participants' conformity assessments across the 16 examples) and then analyzed the unstandardized regression coefficients across participants. The results supported the hypothesis that both social desirability and introspective availability exert independent effects on denials of personal conformity. There was a significant effect of social desirability (mean of unstandardized regression coefficients $=0.22$, $s d=.66$ ), $t(42)=2.26, p=$ .03. And, there was a similarly sized effect of introspective availability $(M=0.21$, $s d=.66)$, $t(42)=2.09, p=.04$. There was no effect of the interaction of these two factors $(M=-0.02$, $s d=$ $.22), t<1$, n.s.

The results of this first study support the notion that people think they are less susceptible than others to conformity pressures. These results also provide evidence that this self-other asymmetry is rooted not only in the perceived undesirability of social influence but also in the tendency for social influences to operate nonconsciously. Participants were more likely to deny undesirable than desirable social influences, but they also were more likely to deny implicit than explicit ones. Importantly, each of these two sources of denial had independent - and additive effects. In our next experiment, we sought further evidence that people's blindness to personal conformity could occur independent of social desirability concerns.

\section{Study 2: Framing the Impact of Social Influence on Trendy Purchases}

It was not keeping up with the Joneses that made her want a Viking range, she said. It was because, as a serious cook who likes to entertain, it had the features she needed.

- Olson (2004)

In this study, college students who owned a trendy electronic gadget rated the impact of social influence on their own purchase, relative to their fellow students. The relevant social influence was framed as either desirable or undesirable. Given the implicit nature of much of social influence (e.g., Chartrand \& Bargh, 1999; Epley \& Gilovich, 1999; Fitzsimons \& Bargh, 2003; Vorauer \& Miller, 1997; Word, Zanna, \& Cooper, 1974), we predicted that participants would deny this influence on their own purchases (relative to their peers' purchases), regardless of whether they were exposed to a socially desirable or undesirable depiction of that influence.

\section{Method}

\section{Participants}

Forty Princeton undergraduates completed a questionnaire in exchange for candy. 


\section{Procedure}

Students were approached on campus and asked if they owned an "iPod" (a popular electronic gadget for playing music). Those who said they did were asked to complete a survey. Of the 100 students queried, 41 reported owning an iPod; one of those 41 declined to participate.

\section{Questionnaire and Experimental Manipulation}

In both experimental conditions the questionnaire began by stating that the researchers were "interested in the factors that influence peoples' decisions to purchase consumer products" such as the iPod. Participants were further told: "People are attracted to products for various reasons. Sometimes, people want a certain product because they really like the particular qualities that the product has to offer. For example, in the case of the iPod, they might like its small size, large memory capacity, clear sound, or sleek and modern styling." A second paragraph delivered the experimental manipulation. That manipulation is indicated below via underlining for the socially desirable condition, and italics for the socially undesirable condition:

While it is [not necessarily wrong / of course a good idea] to buy an iPod for these reasons, sometimes people want certain products for more social reasons. For example, in the case of the iPod, they might notice that their classmates or friends own one and that might affect their interest in having one. Everyday observation, and a good deal of psychological research, suggests that being affected by this type of social influence [is / is not] a good thing. [It helps us to connect with and relate to those around us. It is easier for us to relate to other people if we have things in common or share similar experiences. / By leading us to follow along, it prevents us from thinking for ourselves. It may be easier to follow social norms, but this leads us to sacrifice our individuality.] Thus, doing something as simple as buying an iPod can be a [good thing by strengthening our social connection with other people, and providing an additional dimension on which we can communicate and share experiences. / bad thing by getting in the way of our being true to ourselves, and leading us to go along with what those around us are doing rather than just being ourselves.]

They next provided their assessment based on this description of the "desirability" of being "affected by social influence in getting an iPod" ( 1 = Very undesirable, 5 = Neither desirable nor undesirable, 9 = Very desirable). They then assessed how much they got their iPod "because of social influence" relative to their peers $(1=$ Much less than the average Princeton student, $5=$ Same as the average Princeton student, 9 = Much more than the average Princeton student).

\section{Results and Discussion}

\section{Social Desirability}

The manipulation of social desirability was successful. Participants provided higher assessments of social desirability in the socially desirable version $(M=5.65)$ than in the socially undesirable version $(M=4.05)$ of the survey (and their ratings fell above the neutral midpoint in the desirable condition but below it in the undesirable condition), $F(1,38)=6.02, p=.02$. 


\section{Perceived Conformity}

Across the two desirability conditions, participants perceived themselves as having been less socially influenced than their peers in their iPod acquisitions $(M=3.30$, where $5=$ "same" as peers $), t(38)=6.17, p<.0001$. Moreover, this effect emerged both when conformity was described as undesirable $(M=3.10), t(18)=5.05, p<.0001$, and when it was described as desirable $(M=3.50), t(18)=3.68, p=.002$. Indeed, there was no difference between the two conditions in participants' denials of their relative conformity, $F(1,38)=0.52, p=.48$.

Participants in this study thought that their own trendy purchases were less the result of social influence than the purchases of their fellow students. And, their denials of personal conformity persisted even when that conformity was framed as socially desirable. The results of this study, combined with those of Study 1, suggest that social desirability alone does not fully account for people's blind spot to their conformity. We suggest that another reason is that people consider introspective information more than observable behavior when assessing their own (relative to others') conformity, despite the frequently nonconscious nature of social influence. In the studies that follow, we more directly test this hypothesis about underlying mechanism.

\section{Study 3: The Introspection Illusion and Perceptions of Peer Influence}

In this experiment, participants read about various alleged policy proposals related to life at their university, and they were told whether a group of their fellow students supported each one. After indicating their position on each proposal, they evaluated how much they had been influenced by the group of their peers, and also how much an alleged "other participant” (who agreed with the group on the same number of proposals as the participant) was influenced by it.

\section{Method}

\section{Participants}

Forty-four Princeton undergraduates (27 women and 17 men) were paid for participating.

\section{Procedure}

After providing informed consent, participants proceeded to a computer workstation that presented the experiment. They read that the researchers were conducting a study on "memory and decision-making," and that their task involved reading several proposals. They were told that these proposals dealt with matters of common concern to schools in the "Ivy League" and were slated for discussion at an upcoming meeting of those schools. They further read that before the meeting, each school organized "separate panels of undergraduate and graduate students" in order to gauge support for the proposals, and that they would be shown whether their school's undergraduates supported each proposal. They then were presented with two practice proposals followed by 18 "actual” proposals. The first "actual” proposal was:

The committee moves to standardize all early admissions policies to non-binding "Early Action” rather than binding "Early Decision” policies. This move would provide applicants with greater flexibility in the application and financial decision process, however, it would also severely multiply the amounts of early applications received for 
each school, leading to increased competition for applicants and less security for schools.

Random assignment led each proposal to be both supported and not supported over the total group of participants. Each proposal ended with the statement: The panel of Princeton Undergraduates supports [or, depending on version, does not support] this proposition.

After reading each proposal, participants responded to a question regarding its contents and a question regarding the Princeton panel's position on it (both included to encourage participants to retain this information). They then indicated their own position on the proposal (Support/Do not support). After voting on all the proposals, they were shown their voting record next to the votes of the "Princeton panel," so that the number of proposals on which they had agreed with the panel was evident. They then assessed their conformity to the panel and their relative weighting of thought vs. quantifiable behavioral evidence in making that assessment (see Final Dependent Measures).

In order to obtain participants' perceptions of a peer’s conformity (in the same situation), they next were presented with a voting record that purportedly belonged to another participant in the experiment. They responded to the same set of dependent measures regarding that participant's record. The record was constructed from the participant's own, such that the "other participant" agreed with the panel on the same number of issues as the participant, but with the specific proposals of agreement randomized to give the impression of a different voting record.

\section{Final Dependent Measures}

After viewing their own (or subsequently "another participant's”) voting record, participants assessed how much they believed that record was affected by both social influence (i.e., the "position of the panel of Princeton Undergraduates") and by analysis of the relevant proposal (i.e., "specific thoughts about the contents of each proposal"; $1=$ Not at all influenced, 7 = Extremely influenced). They then reported what information they used to make the above judgments: i.e, how much weight they gave to "the number of propositions for which [your / their] vote agreed with that of the Princeton panel" and to "[your recollections of your / your assumptions of their] thoughts and reasoning about the contents of the propositions" $(1$ = Very little, 7 = Very much). Finally, they were asked to indicate the "approximate" number of propositions (out of 18) on which their (and the other participant's) votes agreed with the panel.

\section{Results and Discussion}

\section{Actual Conformity}

Participants agreed with the position ostensibly held by their peers on the Princeton panel on a mean of 10.55 out of 18 proposals. This level of conformity was highly significant (relative to the expected chance value of 9 out of 18$), t(42)=4.74, p<.0001$.

\section{Perceived Conformity}

Even though their fictitious peer exhibited the same level of conformity as themselves, participants showed asymmetric perceptions of social influence. Repeated measures ANOVA revealed that participants felt that they had been less influenced by the panel of students $(M=$ 
3.07) than had their peer $(M=3.61), F(1,43)=6.79, p=.01$. By contrast, they did not feel that they had been less influenced than their peer by the "contents of each proposal" - indeed, the reverse was true ( $M \mathrm{~s}=5.68$ vs. 5.09), $F(1,43)=5.76, p=.02$. This interaction effect involving judgment target and type of influence was significant, $F(1,43)=10.66, p=.002$.

\section{Consideration of Information}

As can be seen in Figure 1, the information participants reported considering in making their conformity assessments depended on whether they were judging themselves or someone else. This predicted interaction effect (target $X$ information considered) was significant, $F(1,43)$ $=66.76, p<.0001$. When evaluating whether their own votes were influenced by the views of their fellow students, participants reported putting far more weight on the nature of their thoughts about the proposals than on their actual votes, $t(42)=9.22, p<.0001$. By contrast, when judging another student, they reported putting as much weight on that ostensible peer's votes as on that peer's presumed thoughts about the proposals, $t<1$.

When information considered was included as a covariate in the ANOVA, the effect of self/other on conformity assessments fell to nonsignificance, suggesting that information consideration fully mediated the relationship between self_-other and perceived conformity, $F(1$, $85)=1.30, p=.26$. The modified Sobel test (Baron \& Kenny, 1986) confirmed the significance of this reduction, $Z=3.96, p<.0001 .^{2}$ In order to obtain further assurance that differences in information consideration were a source of the asymmetry in conformity assessments, rather than that those differences simply were claimed after-the-fact to justify a perceived difference in conformity, we also examined the relevant alternative model. This model, with information considered as the dependent measure and conformity assessments as the covariate, was highly significant, $F(1,85)=31.92, p<.0001$. Thus, although differences in information consideration fully mediated the effect of self/other on perceived conformity, the reverse was not true.

Our participants reported a self-other divergence in how they weighted conformityrelated information. But can such self reports be trusted? In order to test their validity, we examined whether participants who reported paying more attention to behavioral information in judging conformity did indeed show a stronger relationship between the apparent conformity of that behavior and their subsequent conformity judgments. Indeed, the more participants reported attending to behavior, the stronger a predictor behavior (i.e., number of votes conforming to the panel) was of the amount of conformity they imputed. This analysis was conducted via a test of the interaction effect of actual behavior and reported attention to behavior as a predictor of conformity assessments; the interaction effect was apparent both for self-assessments, $B=.13$, $S E=.06, p=.05$, and other-assessments, $B=.04, S E=.01, p=.009$.

Finally, participants were asked at the end of the study to recall how often their and their peer's votes had agreed with the student panel. Interestingly, they recalled that they had agreed with the panel on fewer propositions $(M=9.91)$ than had their peer $(M=10.98), F(1,43)=6.99$, $p=.01$, even though the two levels of agreement were manipulated to be identical. Participants' recollections tended to be less well correlated with the truth when it came to assessing their own conformity, $r(42)=.46, p=.002$, rather than an alleged peer's conformity, $r(42)=.66, p<$ .0001 , as indicated by a $z$-test of the difference between correlations, $z=1.89, p=.06$. 
The fact that differences in perceived conformity for the self and other persisted in an experiment in which the "other's" responses were in fact merely a scrambled version of participants" own underscores the robustness of the "alone in a crowd of sheep" effect. This study also provides support for our proposed underlying mechanism. When making judgments about their own (vs. others') susceptibility to social influence, participants were more likely to rely on thought-related evidence and less likely to rely on behavioral evidence. Mediational analyses suggested that this difference contributed to the observed blind spot to personal conformity.

This study raises the question of what particular thought-related information our participants considered. They were not exposed to any information about the thoughts of the "other" student whom they evaluated, and one could argue that this lack of access could be responsible for the observed asymmetry in conformity perception. Because we expected that access was not the sole issue, our next study provided observers with access to actors' introspections and made the same predictions as Study 3. Unlike previous studies, this new study also used a between-subjects design (participants assessed self or other) in order to ensure that the self-other difference would emerge even when it was not made explicit.

\section{Study 4: Available Introspections and Perceptions of Voting with the Party}

Participants read descriptions of three political propositions allegedly being reviewed by the state of California. Each one included information about Republicans' and Democrats' purported position on it. They then recorded all of their thoughts on that proposition and indicated how they would vote on it. Finally, they indicated their party affiliation, assessed how much that affiliation influenced their votes, and reported what information they used to make that assessment. Participants in the other condition provided similar ratings of a yoked peer, after reading the propositions and seeing their peer's recorded thoughts, votes, and party affiliation.

\section{Method}

\section{Pilot Testing of Political Issues}

People's political positions can resemble those of their party for reasons other than social influence. For example, people may share goals with their party (e.g., cutting taxes, or protecting the environment) that guide their own and their party's positions. Because we sought to examine perceptions of social influence when that influence could reasonably be thought to have occurred, we required a set of political issues that were not clearly partisan (but to which we would ascribe ostensible partisan support). In pilot testing, we provided undergraduate raters ( $N$ $=12$ ) with four issues and asked them to guess what percentage of Republicans and Democrats would support each one. The three issues selected for this study were perceived as equally likely to be supported by Republicans and Democrats (mean assumed differences in percentage of Democrats vs. Republicans supporting were $10.00 \%, 6.36 \%$, and 5.00\%, all $t$ 's $<1$ ).

\section{Participants}

Sixty-four undergraduates at Stanford University participated in exchange for pay. 


\section{Self Condition Procedure}

Participants in the self condition were told that we were "interested in their opinions on some issues being reviewed in the California legislature.” (All participants resided in California and were likely familiar with the state's proposition system.) They were further told that we were interested in their thoughts while reading each issue and wanted them to record those thoughts as they read. They then were provided with the following thought-listing instructions (Cacioppo \& Petty, 1981) accompanied by a sample thought-listing (about eating vegetables):

The page following each issue is for you to write down your thoughts, so while you read the issue, have that page open as well so you can write as you go. We would like you to record all thoughts as they go through your head. You should be writing thoughts as you read, so don't wait until you're done reading the whole issue to write. The thoughts do not have to be sentences or even fully formed, they can be words or notes, whatever goes through your head. But, they should be everything that goes through you head while you read the issue.

The first issue participants read about was purportedly supported by Democrats and opposed by Republicans, as was the third issue, while the opposite was purportedly true for the second issue. The first issue was:

\section{Max Cargo Size at Port of Los Angeles}

Thousands of jobs and families revolve around the Port of LA, and a tremendous decline in shipping traffic has left many Californians out of work. To combat the decline, some members of the legislature proposed a measure increasing the cargo size allowed at the port, which would hopefully stem the losses to other ports (in and outside US) that allow larger/heavier cargo and increase traffic to the port of LA. Most Democrats support the bill, suggesting it will increase jobs; most Republicans oppose the bill, suggesting it will increase the influx of goods from other countries, hurting US businesses.

After thinking about this first proposition, participants indicated their support for it, both on a dichotomous measure (Oppose/Support) and a continuous scale $(-3=$ Heavily Oppose, $3=$ Heavily Support). After completing this procedure for all three issues, they indicated their party affiliation (Democrat/Republican), the strength of that affiliation (1 = Very Much a Democrat, 7 = Very Much a Republican), and their political orientation (1 = Very Much Liberal, $7=$ Very Much Conservative). They then completed our dependent measures (see below).

\section{Other Condition Procedure}

Each participant in the other condition was randomly yoked to a participant in the self condition and given a copy of that participant's study materials (excluding their dependent measures, but including the descriptions of the political propositions and thought-listing instructions, as well as the participant's recorded thoughts, votes, and party affiliation). A cover sheet informed the participant that the materials came from another subject and that the participant should read the materials and complete the questions about them (see below). 
Perceptions of Conformity 14

\section{Dependent Measures}

Participants first were asked to assess how much their opinions (or the opinions of their voting peer) were influenced by (a) “The views of the political party [you/they] support,” and (b) "[Your/their] thoughts, motives, and opinions." They then were asked to assess how much they considered each of two factors when formulating their answer to the above questions: (a) "Your understanding of the thoughts [you/they] had while deciding [your/their] position," and (b) "The correlation between [your/their] position on each issue and the positions of the party [you/they] support.” Each question was accompanied by a 7-point scale (1 = Not at All, $7=$ Very Much).

\section{Results and Discussion}

\section{Actual Conformity}

Participants voted with the position ostensibly held by their party leadership on a mean of 2.38 out of 3 propositions. This level of conformity was highly significant (relative to the expected chance value of 1.5), $t(31)=10.06, p<.0001$.

\section{Perceived Conformity}

Our first prediction was that participants would perceive their behavior as less reflective of conformity to their party than others would perceive it to be. Indeed, participants providing self-assessments claimed that they were less influenced by their party than their peers thought they were ( $M$ s $=3.97$ vs. 4.84$), F(1,31)=6.05, p=.02$. There was no corresponding difference in perceived influence of personal thoughts ( $M s=5.78$ vs. 5.50$), F=1$, perhaps because participants in the other condition had been given access to those thoughts. The relevant target (self/other) X influence (thoughts/party) interaction was significant, $F(1,31)=5.02, p=.03$.

\section{Consideration of Information}

We next examined self_-other differences in the information participants reported considering in making their judgments of social influence. As predicted, there was a significant interaction of judgment target and information considered, $F(1,31)=7.27, p=.01$. Participants making self-judgments reported considering information about thoughts more than quantifiable behavioral information about the association between their own and their party's positions ( $M s=$ 5.50 vs. 4.09), $t(30)=3.67, p=.0009$. When judging others, participants did not report privileging thoughts over behavior ( $M \mathrm{~s}=5.03$ vs. 5.06), $t<1$. Moreover, reported information considered fully mediated the effect of self/other on perceived conformity. When information considered (i.e., thoughts vs. votes) was included as a covariate, the effect of self/other on conformity assessments fell to nonsignificance, $F(1,61)=.55, p=.46$. The Sobel test confirmed the significance of this reduction, $Z=2.45, p=.01$. A test of the alternative model (with information considered as the dependent measure, and perceived conformity as the covariate) also yielded a nonsignficant result, $F(1,30)=2.37, p=.13$. But, this result did lean towards significance, suggesting that the alternative model was not as good a fit as the proposed one.

Beyond our analyses of participants' self-reports, in this study we also were able to examine whether actors actually did rely on introspective information more than observers. We expected that actors' conforming thoughts would better predict their self-assessments of 
conformity than their peers' assessments of that conformity. In order to test this hypothesis, participants' thought-listings were first coded (by two undergraduates uninformed of our hypotheses) in terms of whether they included thoughts suggestive of possible party influence (e.g., "I support the Republicans"; or "The Democrats are usually right”; inter-rater reliability $\alpha$ $=.83)$. Participants' weighting of introspective information was calculated via the correlation between (a) how many conformity-related thoughts they (or their voting partner) listed, and (b) their assessment of whether they (or their partner) had conformed (rather than voted by personal opinion). As expected, participants who provided self-assessments saw themselves as more conforming when they had generated more conforming thoughts, $r(30)=.58, p=.0007$. No such correlation was found for their observer peers, $r(30)=.06, p=.74$, and these correlations differed significantly, $z=2.29, p=.02$. Similar effects were observed when conforming thoughts were coded dichotomously (i.e., as present vs. absent), $r_{\text {self }}=.60, r_{\text {other }}=.10, z=2.26, p=.02$.

The results of this study provide evidence in a between-subjects design that participants saw their own conforming voting behavior as less socially-influenced than did their participant peers. When making self-assessments, participants also reported paying relatively more attention to thoughts than quantifiable behavior, and this self-other asymmetry mediated the relationship between self/other and assessments of conformity. Notably, these differences in consideration of information seemed to involve differences in valuation of information, rather than just access to it, as observer participants were privy to their voting peers' thoughts and behavior. Our final study more directly examined this hypothesis about valuation of introspections vs. behavior.

\section{Study 5: The Perceived Value of Thought and Behavior Information}

Conformity $n$. Compliance with standards, rules, or laws; behavior in accordance with socially accepted conventions or standards.

-Oxford American Dictionary (2005)

Participants read scenarios describing situations in which people might be socially influenced. These situations were either described as involving the participant him or herself, or as involving other individuals. After reading about each situation, participants chose between two descriptions of what it might mean to "conform" in that situation. One description was always focused on actions and the other on thoughts, feelings and motives. We hypothesized that when primed to think about themselves, rather than others, participants would be more likely to view thoughts, feelings and motives, rather than actions, as most diagnostic of conformity.

\section{Method}

\section{Participants}

Participants were 92 Stanford undergraduates participating in exchange for pay.

\section{Procedure and Questionnaire}

Participants completed a questionnaire describing three scenarios. The first asked them to "Imagine that [you are/Carol is] shopping at a clothing store, and [you are/Carol is] deciding what jeans to buy." They then were asked to indicate "what might it mean" to conform in that situation, by choosing between two options. One option focused on internal information ("While [you are/Carol is] looking at different jeans, [you think/she thinks] about whether [your/her] 
friends have been wearing them") and the other on observable behavior (i.e., "[You end up/Carol ends up] buying a pair of jeans that many of [your/her] friends have been wearing lately").

The other two scenarios were presented in the same fashion. The second scenario asked the participant to imagine that "[You/John] just saw a television commercial with one of [your/his] favorite celebrities pitching a new soft drink," and provided an introspective definition of what it might mean to conform in that situation ("While viewing the commercial, [you are/John is] curious to try an item that this celebrity is endorsing") and a behavioral definition ("At some point after seeing the commercial, [you make/John makes] a trip to the store to purchase this new drink"). In the third scenario, participants were asked to imagine: "[You are/Mark is] out at a restaurant, and most of the people at [your/his] table order the Caesar salad for their first course," and again were provided with an introspective definition ("[You consider/Mark considers] whether to also order the Caesar salad for [your/his] first course") and a behavioral one ("[You order/Mark orders] the Caesar salad for [your/his] first course").

\section{Results and Discussion}

Consistent with our hypothesis, participants showed a self-other asymmetry in whether they chose to define conformity in terms of a thought, feeling or motive, or in terms of an action or observable behavior, $F(1,90)=13.66, p=.0004$. As can be seen in Figure 2, participants choosing definitions of conformity while focused on themselves selected introspective definitions $63 \%$ of the time, whereas participants choosing definitions while focused on another person selected introspective definitions $38 \%$ of the time. This self-other difference was significant for all three scenarios: friends/clothing, $F(1,90)=4.56, p=.04$, celebrity/product endorsement, $F(1,91)=5.34, p=.02$, and norms/dining, $F(1,90)=10.40, p=.002$.

This study supports our contention that information about introspections vs. about behavior is viewed as differentially probative depending on whether it is one's own or another person's conformity that is in question. The standard, dictionary definition of conformity cited at the opening of this study focuses on action ("compliance” and "behavior"). It is thus worthy of note that individuals in this study were inclined to choose a more appropriate definition of conformity in the context of others than themselves. In assessing conformity in themselves, individuals not only focused too much on thoughts (as in our earlier studies), but they also claimed that this focus was consistent with the very meaning of the concept of conformity.

\section{General Discussion}

The hypothesized tendency to see oneself as less susceptible to social influence than others, and to see one's behavior as less conforming, was apparent across five studies. This selfother asymmetry was first documented when participants compared themselves to their classmates across a diverse range of domains (Study 1). It again emerged when they assessed a specific instance of social influence - i.e., peer influence on purchases of a trendy electronic gadget (Study 2). Indeed, the effect emerged even when participants judged others who had conformed to precisely the same degree that they themselves had (Study 3), and even when self vs. other assessments were provided by different participants (i.e., in a between-subjects design; Study 4). In short, our participants were generally quick to recognize the impact of social influence - except when that influence was on themselves. 


\section{The Introspection Illusion}

We have suggested that the observed self-other asymmetry in perceptions of conformity and susceptibility to social influence is afforded by a self-other asymmetry in the cognitive processes that people use to make judgments about self vs. other. We refer to this latter asymmetry as an introspection illusion. It involves a tendency for actors, more than observers, to focus on introspective information and neglect behavioral information. Several studies in this article provide evidence for this illusion and for its influence on perceptions of conformity.

Study 1 offered initial support for the introspection illusion mechanism. Participants in that study were more likely to deny their relative susceptibility to conformity when that conformity was more likely to elude their introspective awareness. Studies 3 and 4 further supported the proposed theoretical mechanism. Participants in those studies reported giving more weight to thoughts than behaviors when assessing their own conformity, but not when assessing others' conformity. This reported difference fully mediated the effect of self/other on conformity assessments in both studies. Our evidence for an introspection illusion also went beyond selfreport. Participants in Study 4 relied on the conforming nature of their thoughts in assessing whether they had been socially influenced, whereas their peers - who also were privy to those thoughts - were not similarly responsive to them.

We have suggested that differences in consideration of internal information stem not only from differences in access to that information, but also from differences in its perceived diagnostic value. Our findings support this hypothesis. In Study 4, observers who were privy to actors' relevant thoughts did not privilege introspections over behavior. In Study 5, participants claimed that introspective information (as opposed to behavioral information) was more valid for diagnosing conformity when that conformity was their own, rather than someone else's.

The introspection illusion involves a tendency for people to weigh thoughts more for self than others and to weigh behavior less. Because conformity is generally defined in terms of behavior, people's strong reliance on their thoughts at the expense of consulting their actions is noteworthy. By disregarding their behavior, our participants failed to detect something about themselves that most outsiders could easily see. Although considerations of introspections vs. actions are often inextricably linked, in this research participants' willingness to ignore their own behavior is perhaps even more surprising than their faith in the value of their introspections. Although the term introspection illusion emphasizes self-other differences in the faith that people place in their introspections, a necessary component of it involves the neglect with which people treat their own behaviors. The concepts of an introspection illusion and of what might be called "behavioral disregard" are in this way two sides of a coin.

Finally, we have noted that reliance on introspective information is likely to blind people to instances of their own conformity because, at least in Western cultures, social influence often operates nonconsciously. In future research it would be interesting to examine whether people in more interdependent cultures such as East Asian cultures, where conscious thoughts about conformity are more common (Kim \& Markus, 1999), would be less likely to deny their own susceptibility to social influence. 


\section{Self-Enhancement and Perceptions of Conformity}

In this research, we also considered the question of whether the observed asymmetry in perceived conformity reflected a "mere" tendency to self enhance. People generally tend to see themselves as better-than-average across a wide range of traits and abilities, and it was thus worth considering whether the present phenomenon was just another example of that tendency.

Our results argue against a purely motivational explanation. In Study 1, participants saw themselves as less susceptible to social influence than their peers, and this effect was attributable not only to motivation (and the desirability of the relevant form of social influence) but also to cognition (and the introspective availability of that social influence). In Study 2, we found that participants denied their relative susceptibility to social influence in the case of a specific behavior (acquiring an iPod music player), even when they were induced to view that behavior as desirable. A number of other findings also are suggestive that self-enhancement concerns did not fully account for the observed conformity blind spot. In Study 4, participants saw themselves as less susceptible to social influence than their peers even when those comparisons were made across participants and participants were thus unable to assert any relative superiority. Moreover, although the classic better-than-average tendency is often eliminated when the comparison target or quality being judged is described in more concrete terms (Alicke et al., 1985; Dunning, Meyerowitz, \& Holzberg, 1989), we found that the observed self-other asymmetry occurred even when participants judged a specific person and a specific behavior (Studies 3 and 4). ${ }^{3}$

Yet, the source of self-other asymmetry we propose need not operate without concern for motives and desires. Participants in Study 1 were more likely to deny their susceptibility to more negative forms of social influence than more positive ones. But, participants in Study 2 reported that social influence affected their own iPod purchases less than their peers' purchases, even when they were led to view that influence as desirable. Taken together, these results suggest that the relevant asymmetry in conformity perception is likely to involve an interplay of motivational processes (involving a desire to disavow negative traits) and cognitive processes (involving weighting of introspective vs. behavioral information). Though our participants were likely motivated to see themselves in a positive light by denying their susceptibility to unwanted social influence (and, perhaps, claiming their susceptibility to desirable social influence), their efforts were likely constrained by their illusions about the value of their own introspections.

\section{Self-other Asymmetries}

Social psychologists have generally focused their attention either on how people perceive themselves, or on how they perceive other people, but not both. The present research contributes to a tradition concerned with how individuals perceive themselves versus how they perceive other people, and with why these differences occur and what their consequences might be (e.g., Andersen \& Ross, 1984; Jones \& Nisbett, 1972; McGuire \& McGuire, 1986; Prentice, 1990). In addition to identifying a robust difference in the perception of self versus others, the present research may also contribute to our understanding of self-other asymmetries more generally. In some ways, this research takes up a story begun by Jones and Nisbett (1972) about differences in the inferences and attributions people make about themselves versus other actors. It suggests that an important difference in the way actors perceive themselves, versus how others perceive them, involves the reliance that actors vs. observers place on introspective vs. behavioral information. 
In the context of conformity judgments, the introspection illusion may seem to contradict the classic actor-observer bias whereby individuals attribute their own behavior to the situation but others' behavior to those others' dispositions. The introspection illusion suggests that actors will deny the influence of others (an apparently external factor) on their actions, while imputing the influence of private thoughts (an apparently internal factor) on those actions. However, a more careful analysis suggests that the introspection illusion dovetails nicely with the classic actor-observer bias. By focusing on internal states, one is likely to find one's attention drawn to the immediate external circumstances that prompted those states. Thus, the luxury car owner who looks to his feelings and thoughts about his car purchase is likely to think of external factors that prompted his internal response to it - in this case, qualities of the car (rather than social factors, which likely operated implicitly). Similarly, in the case of observer assessments, the behavioral focus described by the introspection illusion parallels the dispositionist focus described by the actor-observer bias. In focusing on behavior when making assessments about others, one will likely infer dispositional traits from that behavior (Jones \& Davis, 1965).

Another theory involving the nature of self and social perception that is worth considering in the present context is Bem's (1972) self-perception theory. Bem's suggestion that people infer their attitudes from their behavior may seem to contradict our contention that people largely disregard their behavior in judging their conformity. This apparent contradiction can be resolved by Bem's claim that inferences based on behavior are likely to occur when internal cues as to one's attitude are "weak, ambiguous, or uninterpretable” (p. 2), but when one is nevertheless called upon to express an attitude. The circumstance we describe is somewhat different: individuals are likely to feel that they have plenty of internal cues as to whether or not they have conformed (e.g., I never thought about buying my car to fit in, but I did think quite a bit about how much I liked its handling), but that none of these cues point to conformity.

\section{Some Consequences of Seeing Oneself as Alone in a Crowd of Sheep}

Asymmetric perceptions of susceptibility to social influence are likely to foster conflict and misunderstanding, particularly when others' behavior is different from our own. When others seem to see the world differently from how we do, we tend to see our views as objective and correct, and theirs as irrational and wrong (Pronin, Gilovich, \& Ross, 2004). In cases where those others' views or actions resemble those around them, such as when we observe "fratboys” drinking alcohol to excess, or "fanatic extremists" sacrificing their lives for a cause, we may see them as guided by irrational conformity - even while we claim that our views and actions derive from rational analysis and independent thought. This difference in perception is likely to exacerbate conflict, as those on each side find themselves not only disagreeing about the relevant issues but also seeing their rival as irrationally closed-minded, and blindly conforming.

We live in a social world, and our views, decisions, and behaviors are influenced by those around us in countless ways. Yet each of us believe, like the "great man" in the Emerson quotation that began this article, that we alone, in the midst of the crowd, resist the pressure to live after the world's opinion. It is interesting to consider what life would be like if people instead assumed that, when it came to conformity and social influence, what was true of others was likely to also be true of themselves. In the meantime, we are likely to continue believing that we are "alone in a crowd of sheep." 


\section{References}

Alicke, M. D., Klotz, M. L., Breitenbrecher, D. L., Yurak, T. J., \& Vredenburg, D. S. (1995). Personal contact, individuation, and the better-than-average-effect. Journal of Personality and Social Psychology, 68, 804-825.

Allport, G.W. (1985). The historical background of social psychology. In G. Lindzey \& E. Aronson (Eds.), The handbook of social psychology. New York: Random House.

Andersen, S.M., \& Ross, L. (1984). Self-knowledge and social inference: I. The impact of cognitive/affective and behavioral data. Journal of Personality and Social Psychology, 46, 280-293.

Asch, S. E. (1956). Studies of independence and conformity: A minority of one against a unanimous majority. Psychological Monographs, 70 (Whole no. 416).

Baron, R. M., \& Kenny, D. A. (1986). The moderator-mediator variable distinction in social psychological research: Conceptual, strategic and statistical considerations. Journal of Personality and Social Psychology, 51, 1173-1182.

Bem, D. J. (1972). Self-perception theory. In L. Berkowitz (Ed.), Advances in experimental social psychology (Vol. 6). New York: Academic.

Burnkrant, R.E., \& Cousineau, A. (1975). Informational and normative social influence in buyer behavior. Journal of Consumer Research, 2, 206-215.

Cacioppo, J.T., \& Petty, R.E. (1981). Social psychological procedures for cognitive response assessment: The thought listing technique. In T. Merluzzi, C. Glass, \& M. Genest (Eds.), Cognitive assessment. New York: Guilford Press.

Chartrand, T.L., \& Bargh, J.A. (1999). The chameleon effect: The perception-behavior link and social interaction. Journal of Personality and Social Psychology, 76, 893-910.

Cialdini, R. B. (2003). Creating normative messages to protect the environment. Current Directions in Psychological Science, 12, 105-109.

Cohen, G. L. (2003). Party over policy: The dominating impact of group influence on political beliefs. Journal of Personality and Social Psychology, 85, 808-822.

Dunning, D., Meyerowitz, J. A., \& Holzberg, A. D. (1989). Ambiguity and self-evaluation: The role of idiosyncratic trait definitions in self-serving assessments of ability. Journal of Personality and Social Psychology, 57, 1082-1090.

Emerson, R. W. (1841). Essays. Boston: J. Munroe and Company.

Epley, N., \& Dunning, D. (2000). Feeling "holier than thou”: Are self-serving assessments produced by errors in self- or social prediction? Journal of Personality and Social Psychology, 79, 861-875.

Epley, N., \& Gilovich, T. (1999). Just going along: Nonconscious priming and conformity to social pressure. Journal of Experimental Social Psychology, 35, 578-589.

Fitzsimons, G. M., \& Bargh, J. A. (2003). Thinking of you: Nonconscious effects of relationship representations on goal pursuit. Journal of Personality and Social Psychology, 84, 148164.

Ionesco, Eugene. (1961). Rhinocéros. New York: Holt, Rinehart and Winston.

Jones, E.E., \& Davis, K.E. (1965). From acts to dispositions: The attribution process in person perception. In L. Berkowtiz (Ed.), Advances in experimental social psychology, 2 (pp. 219-266). New York: Academic Press.

Jones, E. E., \& Nisbett, R. E. (1972). The actor and the observer: Divergent perceptions of the causes of behavior. In E. E. Jones et al. (Eds.), Attribution: Perceiving the causes of behavior. Morristown, NJ: General Learning Press. 
Kim, H., \& Markus, H. R. (1999). Deviance or uniqueness, harmony or conformity? A cultural analysis. Journal of Personality and Social Psychology, 77, 785-800.

Kruger, J., \& Gilovich, T. (2004). Actions, intentions, and self-assessment: The road to selfenhancement is paved with good intentions. Personality and social Psychology Bulletin, 30, 328-339.

Kunst-Wilson, W.R., \& Zajonc, R.B. (1980). Affective discrimination of stimuli that cannot be recognized. Science, 207, 557-558.

Latane, B., \& Darley, J. M. (1968). Group inhibition of bystander intervention in emergencies. Journal of Personality and Social Psychology, 10, 215-221.

McGuire, W. J., \& McGuire, C. V. (1986). Differences in conceptualizing self versus conceptualizing other people as manifested in contrasting verb types used in natural speech. Journal of Personality and Social Psychology, 51, 1135-1143.

Milgram, S. (1974). Obedience to authority. New York: Harper \& Row.

Newcomb, T. L. (1943). Personality and social change: Attitude formation in a student community. New York: Dryden Press.

Olson, E. (2004, August 1). A kitchen that says Iron Chef, not Mrs. Cleaver. The New York Times, online.

Prentice, D. A. (1990). Familiarity and differences in self- and other-representations. Journal of Personality and Social Psychology, 59, 369-383.

Prentice, D. A., \& Miller, D. T. (1996). Pluralistic ignorance and the perpetuation of social norms by unwitting actors. In M. P. Zanna (Ed.), Advances in experimental social psychology, 28 (pp. 161-209). San Diego, CA: Academic Press.

Pronin, E., Gilovich, T., \& Ross, L. (2004). Objectivity in the eye of the beholder: Divergent perceptions of bias in self versus others. Psychological Review, 111, 781-799.

Pronin, E., Kruger, J., Savitsky, K., \& Ross, L. (2001). You don't know me, but I know you: The illusion of asymmetric insight. Journal of Personality and Social Psychology, 81, 639656.

Pronin, E., \& Kugler, M. B. (2006). Valuing thoughts, ignoring behavior: The introspection illusion as a source of the bias blind spot. Journal of Experimental Social Psychology, in press.

Pronin, E., Lin., D.Y., \& Ross L. (2002). The bias blind spot: Perceptions of bias in self versus others. Personality and Social Psychology Bulletin, 28, 369-381.

Schachter, S., \& Singer, J. E. (1962). Cognitive, social, and physiological determinants of emotional state. Psychological Review, 69, 379-399.

Sherif, M. (1936). The psychology of social norms. New York: Harper \& Brothers.

Sherif, M. (1937). An experimental approach to the study of attitudes. Sociometry, 1, 90-98.

Thoreau, H. D. (1850/1906). Journal.

Vorauer, J. D., \& Miller, D. T. (1997). Failure to recognize the effect of implicit social influence on the presentation of self. Journal of Personality and Social Psychology, 73, 281-295.

Whyte, W.H. (1956). The organization man. Oxford, England: Simon \& Schuster.

Word, C. O., Zanna, M.P., \& Cooper, J. (1974). The nonverbal mediation of self-fulfilling prophecies in interracial interaction. Journal of Experimental Social Psychology, 10, 109120.

Zajonc, R.B. (1968). Attitudinal effects of mere exposure. Journal of Personality and Social Psychology, 9, 1-27. 


\section{Author Note}

Emily Pronin, Department of Psychology, Princeton University; Jonah Berger, Graduate School of Business, Stanford University; Sarah Molouki, Department of Psychology, Princeton University (now at the Department of Psychology, University of California, Los Angeles).

This research was supported in part by research funds from Princeton University provided to Emily Pronin and to Sarah Molouki. Portions of this research were presented at the 2005 annual meeting of the Society for Personality and Social Psychology.

Our gratitude goes to Tracy Dobie, John Fleming, Elana Jacobs, Lisa Lamb, and Ran Li, for research assistance with various aspects of this project, and to Dena Gromet and Kathleen Kennedy for serving as raters for Study 3. We thank Deborah Prentice and Vincent Yzerbyt for helpful comments and suggestions about this research.

Correspondence concerning this article should be addressed to Emily Pronin, Department of Psychology, Green Hall, Princeton University, Princeton, New Jersey, 08544-1010. E-mail: epronin@princeton.edu. 


\section{Footnotes}

${ }^{1}$ Verbatim descriptions of all influences used in our research are available on request.

2 Because this study used a repeated measures design, these analyses were conducted by adding a condition code for self and other and then conducting the analyses as though the study were a between-subjects design with the condition code as the independent variable. This approach is slightly conservative because of the added noise introduced by treating a given participant's ratings as independent of each other. The same approach was used for dealing with the repeated measures design (involving yoked dyads) of Study 4.

3 Another recent study from our laboratory, which we briefly report here in order to limit the length of this article, suggests that differences in consideration of introspective vs. behavioral information also cannot be attributed to a motive to deny personal conformity. Participants described a "specific occasion" on which they $(n=49)$ or a peer $(n=52)$ did something that "was influenced by conformity (i.e., [your/their] behavior was influenced by what other people were doing)." They then were asked to explain why they believed conformity had occurred. Coding of these explanations in terms of their reliance on thought vs. behavioral information (by 3 raters uninformed of our hypotheses; Cronbach's $\alpha=.73$ ) revealed the predicted self-other difference in consideration of thoughts vs. behavior, $F(1,99)=15.69, p<.0001$. Thus, differential consideration occurred even when it did not promote denials of conformity. 
Figure 1. Reported information considered when judging the impact of social influence on oneself and on an alleged peer (Study 3).

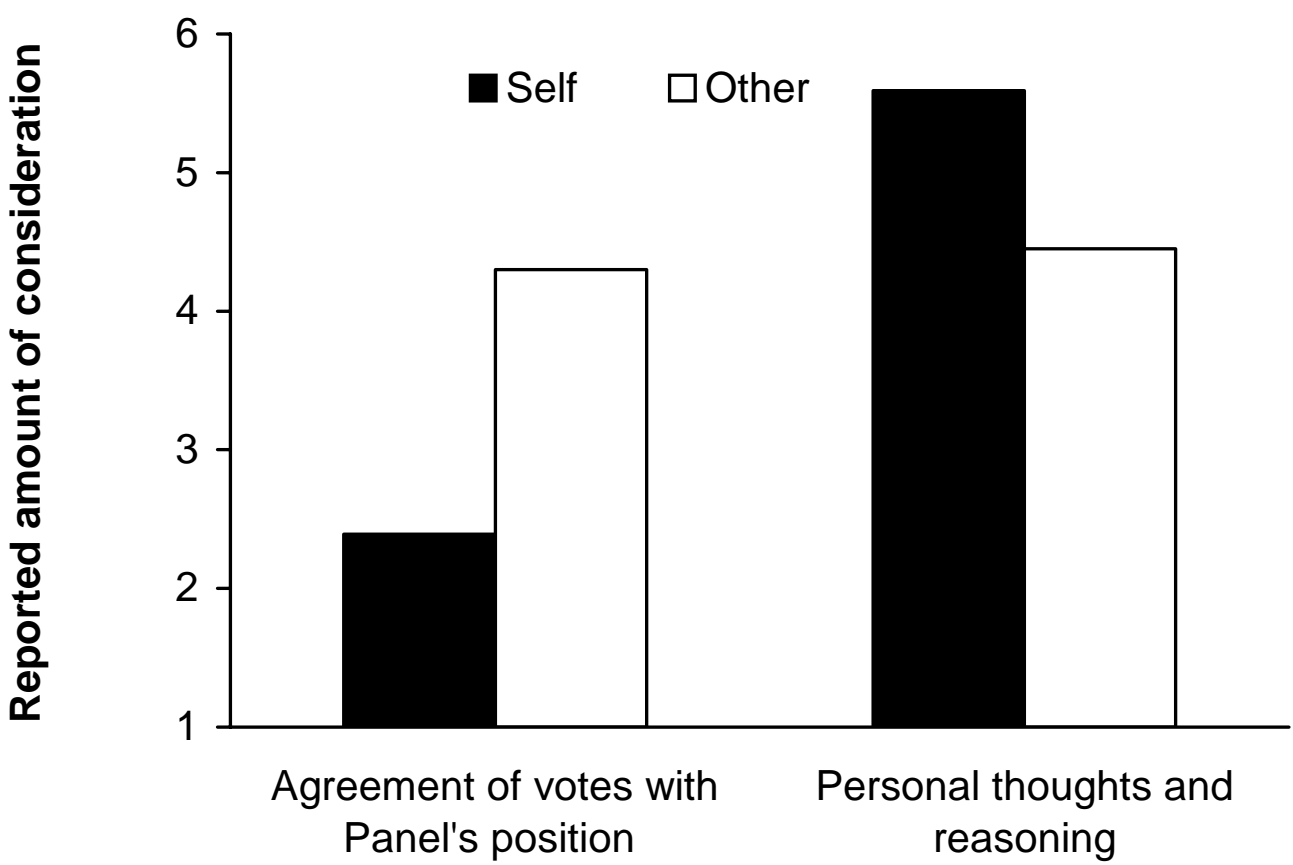

Type of information 
Figure 2. Definition viewed as correct for defining conformity in the participant or in another person (Study 5).

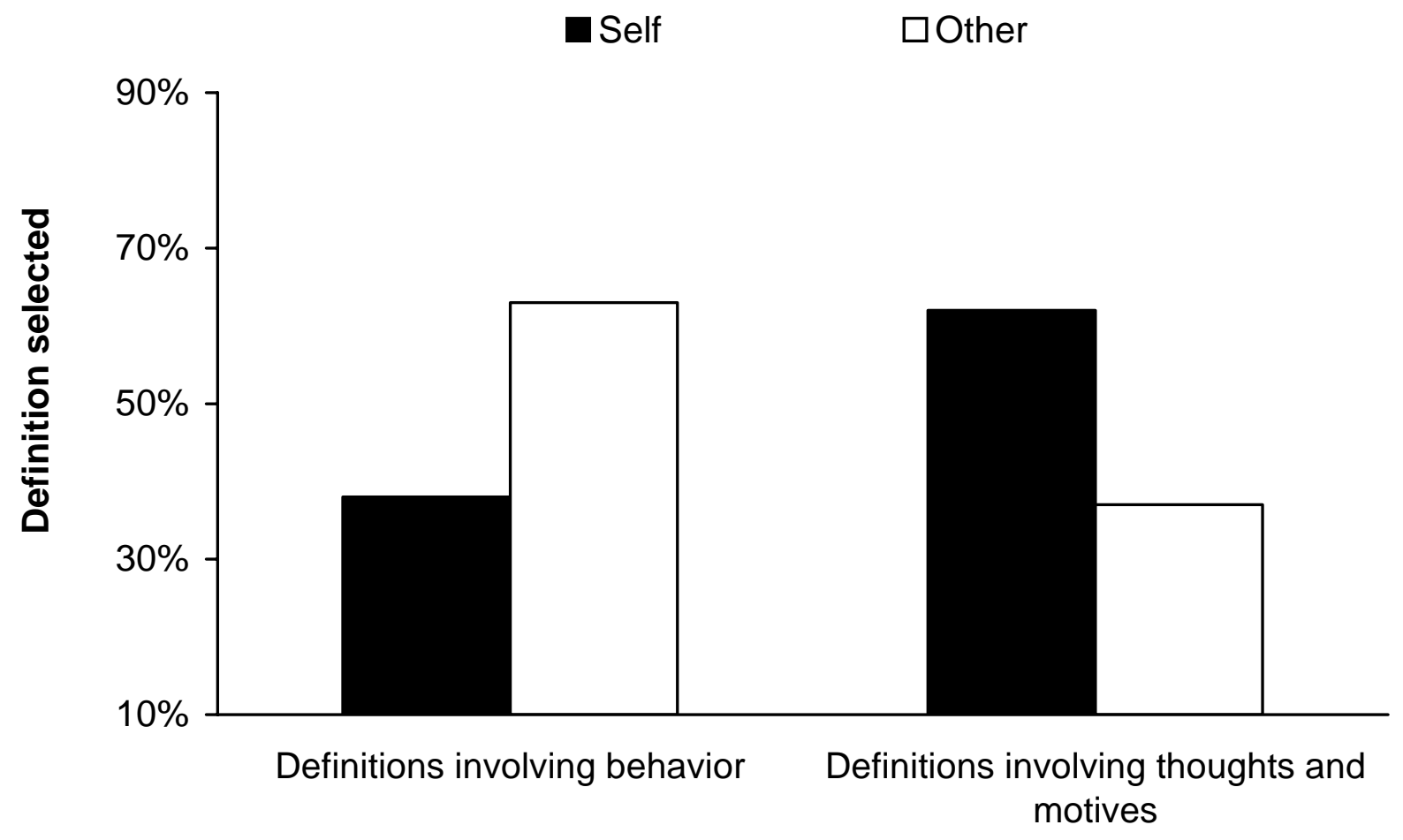

